\title{
Idiopathic Calcium Pyrophosphate Dihydrate (CPPD) Crystal Deposition Disease in a Young Male Patient : A Case Report
}

\begin{abstract}
Calcium pyrophosphate dihydrate (CPPD) crystal deposition disease is a disease of the elderly and extremely rare in young individuals. If young people develop CPPD crystal deposition disease, it may be associated with metabolic diseases such as hemochromatosis, hyperparathyroidism, hypophosphatasia, hypomagnesemia, Wilson's disease, hypothyroidism, gout, acromegaly, and X-linked hypophosphatemic rickets. Therefore, in young-onset polyarticular CPPD crystal deposition disease, investigation for predisposing metabolic conditions is warranted. We report a case of a young male patient with idiopathic CPPD crystal deposition disease, who did not have any evidences of metabolic diseases after thorough evaluations. As far as we know, this is the first report of a young male patient presented with idiopathic CPPD crystal deposition disease.
\end{abstract}

Key Words : Calcium Pyrophosphate; Chondrocalcinosis; Idiopathic Calcium Pyrophosphate Dihydrate (CPPD) Crystal Deposition Disease; Young Male

\author{
Joong Kyung Ahn, Hyung Jin Kim, \\ Eung Ho Kim, Chan Hong Jeon, \\ Hoon-Suk Cha, Chul Won Ha*, \\ Joong Mo Ahn', Eun-Mi Koh
}

Departments of Medicine, Orthopedic Surgery* and Radiology ${ }^{\dagger}$, Samsung Medical Center, Sungkyunkwan University School of Medicine, Seoul, Korea

Received : 9 October 2002

Accepted : 13 December 2002

Address for correspondence

Eun-Mi Koh, M.D.

Department of Medicine, Samsung Medical Center Sungkyunkwan University School of Medicine, 50 Ilwon-dong, Gangnam-gu, Seoul 135-230, Korea Tel : +82.2-3410-3439, Fax : +82.2-3410-3849 E-mail : debate@empal.com

\section{INTRODUCTION}

Calcium pyrophosphate dihydrate (CPPD) crystal deposition disease is characterized by the deposition of CPPD crystals in the articular cartilage visualized as intra-articular calcifications (chondrocalcinosis), identification of the crystals in the synovial fluid, and acute arthropathy (1). Radiographic surveys show an age-related increase of chondrocalcinosis and by the ninth decade almost $50 \%$ of individuals have chondrocalcinosis (2). However, the prevalence of chondrocalcinosis or CPPD crystal deposition disease is not known in Korea. The gender distribution of CPPD crystal deposition disease has differed among large studies $(3,4)$. The manifestations of CPPD crystal deposition disease include incidental finding of chondrocalcinosis, acute attack of arthritis (pseudogout), and chronic arthritis. The knee is the most commonly involved joint, followed by the wrist, metacarpophalangeal, hips, shoulder, and ankle joints (5).

In young patients who are under $40 \mathrm{yr}$ old, chondrocalcinosis is an unusual finding. Chondrocalcinosis in young age is known to be associated with a variety of endocrine and metabolic conditions (6). If the patient is younger than $55 \mathrm{yr}$, it is reasonable to search for metabolic causes. There are five or fewer case reports about CPPD crystal deposition disease in Korea and all these cases developed in old age (7-11). The number of case reports on the idiopathic CPPD crystal deposit disease in young individuals is notably limited $(12,13)$ and in Korea no such cases have been reported in the literature. Thus, we report the first case of a young male patient who presented with idiopathic CPPD crystal deposition disease at the age of $29 \mathrm{yr}$.

\section{CASE REPORT}

A 29-yr-old male patient was admitted to the orthopedic ward of our hospital because of recurrent swelling, stiffness, and severe pain involving the right knee in 2001. Arthroscopic synovectomy and irrigation for the right knee joint was done due to recurrent, progressive episodic events. After that, the rheumatologists were consulted because of chondrocalcinosis of both knee joints on plain radiography. He first developed pain and swelling on the right knee after falling down during skiing back in 1998. He had experienced recurrent swelling, severe pain in both knees occurring three or four times a year, and had been treated symptomatically. Acute attacks of arthritis of both knee joints were self-limiting and resolved usually within 2-3 weeks. Other joints were asymptomatic. He had no family history of joint diseases. On examination, there was swelling, painful restriction of movement in his right knee 


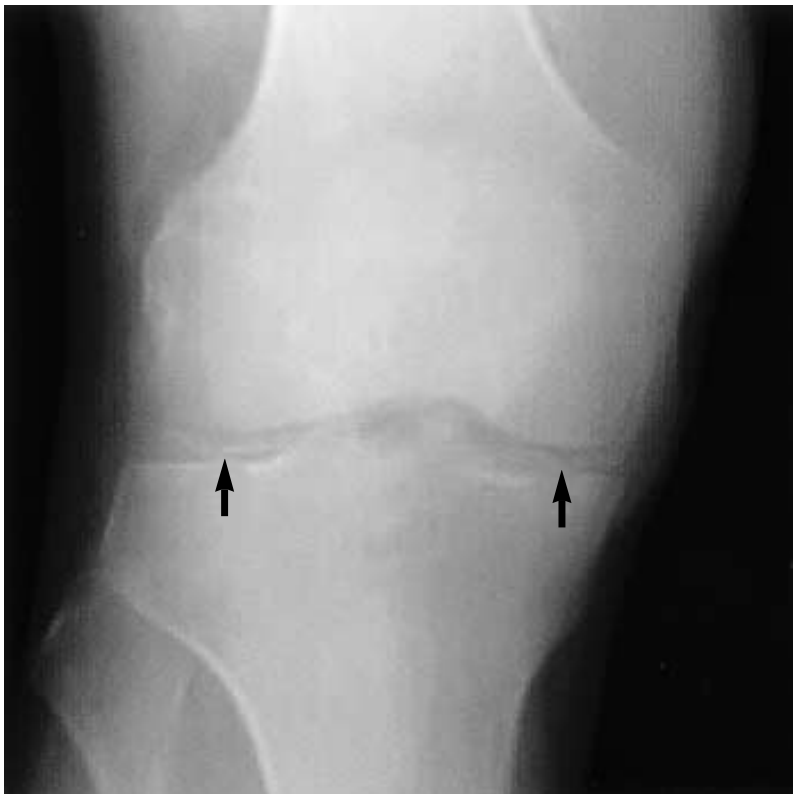

Fig. 1. Radiographs of the anterior-posterior views of right knees showing linear calcifications in the areas of the medial and lateral menisci of the knee, consistent with chondrocalcinosis (arrow).

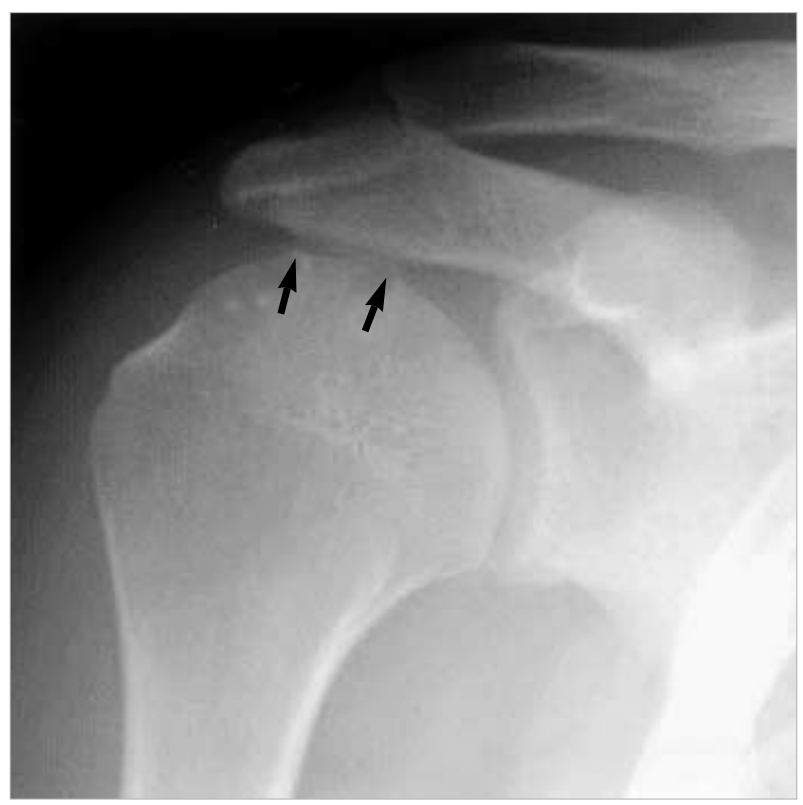

Fig. 3. A radiograph of the right shoulder showing calcification in the chondral cartilage of the proximal humerus.

joint. The right elbow joint had a limited range of motion to that of 90 degrees due to dislocation as an adolescent. Other examinations were unremarkable. Radiographic studies of the affected knee joint revealed typical articular chondrocalcinosis in such areas as the retropatellar cartilage, the medial and lateral menisci with narrowing of the joint space in the patellofemoral compartment (Fig. 1). Calcification was noted even in asymptomatic joints such as chondral cartilage of the prox-
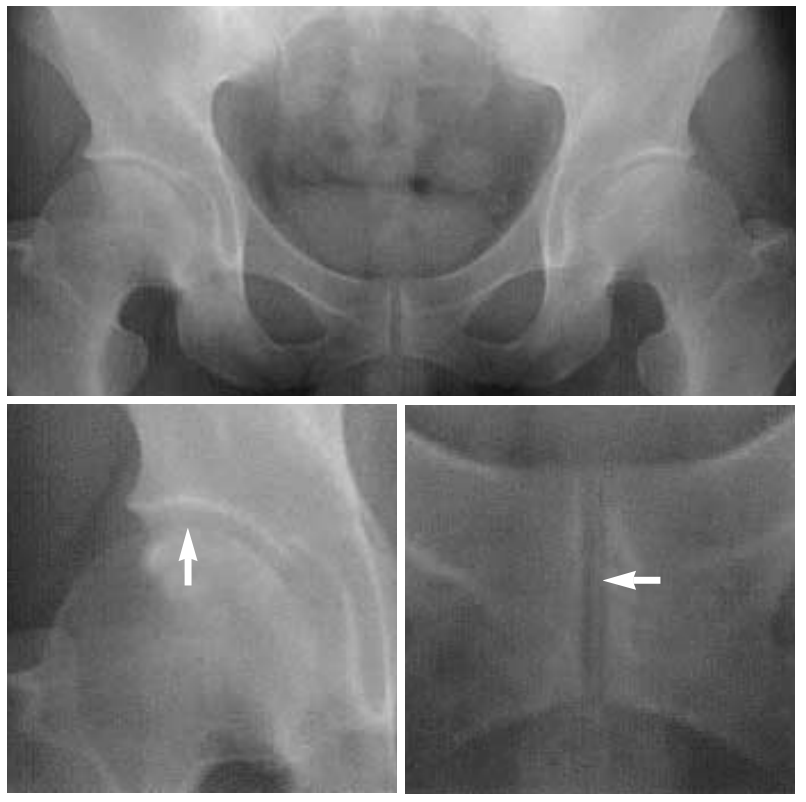

Fig. 2. A radiograph of the pelvis showing typical articular chondrocalcinosis of the symphysis pubis and both hip joints.

imal humerus of both shoulders and the symphysis pubis in plain radiographs (Fig. 2, 3). Moreover, radiographs of both wrists showed chondrocalcinosis of the triangular fibrocartilage of the wrist. To differentiate metabolic conditions associated with CPPD deposition, the evaluation included calcium, phosphorous, alkaline phosphatase, thyroid function test, iron and copper studies, as well as liver MRI. Laboratory investigations showed a white cell count of $8,600 / \mu \mathrm{L}$, hemoglobin $14.6 \mathrm{~g} / \mathrm{dL}$, platelet $281,000 / \mu \mathrm{L}, \mathrm{Na}^{+} / \mathrm{K}^{+} / \mathrm{Cl}^{-} 139 / 3.9 / 99$ $\mathrm{mmol} / \mathrm{L}$, calcium/phosphate $9.4 / 3.8 \mathrm{mg} / \mathrm{dL}, \mathrm{Mg}^{++} 2.1 \mathrm{mg} /$ $\mathrm{dL}$, uric acid $5.1 \mathrm{mg} / \mathrm{dL}$, ESR $4 \mathrm{~mm} / \mathrm{hr}$ (Westergren method), CRP 1.65 mg/dL, ALP 105 U/L, Fe $2.1 \mu \mathrm{g} / \mathrm{dL}$, TIBC $318 \mu \mathrm{g} /$ $\mathrm{dL}$ (normal range: $250-425 \mu \mathrm{g} / \mathrm{dL}$ ), ferritin $182.1 \mathrm{ng} / \mathrm{mL}$, ceruloplasmin $31.6 \mathrm{mg} / \mathrm{dL}$ (normal range $25-63 \mathrm{mg} / \mathrm{dL}$ ), 24 hr urine copper $41 \mu \mathrm{g} /$ day (reference range $<38 \mu \mathrm{g} /$ day), 24 hr urine Fe $46.5 \mu \mathrm{g} /$ day (normal range 100-300 $\mu \mathrm{g} /$ day), T3 by RIA $113 \mathrm{ng} / \mathrm{dL}, \mathrm{T} 4$ by RIA $9.3 \mu \mathrm{g} / \mathrm{dL}$, TSH $1.4 \mu \mathrm{IU} /$ $\mathrm{mL}$ and intact PTH $12.9 \mathrm{pg} / \mathrm{mL}$. Findings of liver MRI were normal. We could not find a metabolic disorder predisposing the young patient to CPPD crystal deposition.

A biopsy of the synovium showed chronic synovitis with villous hypertrophy. Intracellular calcium pyrophosphate crystals were not observed in aspirated synovial fluid and synovium under compensated polarized microscope. However, this patient's clinical and radiologic findings satisfied the possible diagnosis for idiopathic CPPD crystal deposition disease, that is, recurrent, acute, self-limiting synovitis, and chondrocalcinosis of target joints such as knee, shoulder, wrist, and symphysis pubis (3). He was treated with naproxen ( $1 \mathrm{~g} /$ day) and is now on follow-up without recurrence of symptoms. 


\section{DISCUSSION}

CPPD is a calcium salt that is deposited in hyaline and fibrocartilage, appearing as chondrocalcinosis on radiologic finding (14). The exact mechanism of CPPD crystals deposition in joints is not completely understood. CPPD crystal deposition may be influenced by the elevated level of inorganic pyrophosphate (PPi) in joints $(6,15)$. CPPD crystal deposition may be an incidental finding, or may be associated with severe clinical symptoms including arthritis (6). Asymptomatic chondrocalcinosis is the most common clinical finding of CPPD deposition. CPPD can also be released as a crystal into a joint, causing acute painful arthritis called pseudogout. Symptoms of acute pseudogout closely resemble those of any acute arthritis including gout and infection. Even though the presentation of pseudogout is similar to that of gout, attacks of pseudogout tend to be less painful and take longer to reach peak intensity than gout. Large joints are affected more commonly than small joints (14). The joints most commonly involved in an acute attack differ between gout and pseudogout. Almost half of all acute attacks of pseudogout involve the knees, although nearly all joints may be affected.

The diagnosis of CPPD crystal deposition diseases is largely based on the presence of positively birefringent intracellular CPPD crystals and/or typical cartilage or joint capsule chondrocalcinosis on radiographic finding. In contrast to monosodium urate crystals in acute gouty arthritis, CPPD crystals are more difficult to detect because of the smaller size and only weak or no positive birefringence. As in the present case, CPPD crystal in chronic arthritis may be only intermittently present on serial synovial fluid samplings (5). In addition, CPPD crystal may not be seen in joint samples because joint tissues were smashed to piece under arthroscopy. The managements in general include analgesics and NSAID, physiotherapy, intraarticular injection, and surgery, although the optimal treatment has not been established.

According to the presence or absence of recognized predisposing factors, arthritis associated with CPPD crystal deposition is classified as hereditary, idiopathic (sporadic), or associated with various metabolic diseases or trauma. Most cases of CPPD deposition disease are idiopathic. Advanced age is the most common risk factor for the development of CPPD crystal-associated arthritis. CPPD crystal deposition disease, although very rare in young adults, can occur in some young patients if there is a history of an injury to or an operation performed on a joint, or if there is a family history of the disease, or the individual has other diseases that may increase the susceptibility to CPPD crystal deposition disease. Most patients with the familial disease show an autosomal dominant inheritance (5). It has been reported that chondrocalcinosis can occur in a young athlete, possibly after repetitive joint insult (16). Trauma-induced chondrocalcinosis tends to be monoarticular, involving the traumatized joint. In the present case, the patient had neither a family history nor a past or present repet- itive trauma history associated with CPPD crystal deposition disease.

A variety of metabolic and endocrine disorders are associated with the illness, particularly among young patients. Hemochromatosis is the only disease clearly associated with the CPPD crystal-related joint disease $(17,18)$. Other rare metabolic diseases that predispose the patients to CPPD deposition include hyperparathyroidism (19), hypophosphatasia (20), hypomagnesemia (21), Wilson's disease (22), hypothyroidism $(22,23)$, acromegaly, and X-linked hypophosphatemic rickets (18).

In general, associated metabolic diseases and familial predisposition are rarely identified in CPPD deposition disease (24) and routine screening for hereditary or metabolic diseases is not warranted in all CPPD patients. However, further investigation for the predisposing metabolic condition is warranted in young-onset polyarticular chondrocalcinosis (2) because CPPD crystal deposition disease may sometimes be an important clue for detecting other treatable and preventable conditions. Also, screening of asymptomatic family members is important since life-threatening complications can be avoided by instituting appropriate treatments if hemochromatosis, hypomagnesemia, or hypophosphatasia are confirmed (17).

In summary, we report an unusual case of CPPD deposition disease in a young patient who did not have any predisposing or associated disease or hereditary causes. We believe this is the first case of such disease in Korea.

\section{REFERENCES}

1. McCarty DJ. Calcium pyrophosphate dihydrate crystal deposition disease. Arthritis Rheum 1976; 19 (Suppl 3): 275-85.

2. Halverson PB, Ryan LM. Arthritis associated with calcium-containing crystals. In: Klippel JH, Crofford LJ, Stone JH, Weyand CM, editors, Primer on the Rheumatic Diseases, 12th ed. Georgia: Arthritis Foundation 2001; 299-301.

3. Rosenthal AK, Ryan LM. Calcium pyrophosphate crystal deposition disease, pseudogout, and articular chondrocalcinosis. In: Koopman WJ, editor, Arthritis and Allied Conditions, 14th ed. Philadelphia: Williams and Wilkins 2000; 2348-71.

4. Dieppe PA, Aleander GJ, Jones HE, Doherty M, Scott DG, Manhire A, Watt I. Pyrophosphate arthropathy: a clinical and radiological study of 105 cases. Ann Rheum Dis 1982; 41: 371-6.

5. Doherty M, Dieppe P. Clinical aspects of calcium pyrophosphate dihydrate crystal deposition. Rheum Dis Clin North Am 1988; 14: 395-414.

6. Doherty M. Crystal-related arthropathies. In: Klippel JH, Dieppe PA, editors, Rheumatology, 2nd ed. London: Mosby Year Book Europe 1998; 8.16. 1-12.

7. Lee HK, Lee SH, Lee YI, Chung SS, Kang HS, Kim WH, Chung DH. Calcium pyrophosphate dihydrate (CPPD) crystal deposition disease of knee joint: a case report. J Korean Orthop Assoc 1991; 26 : 1600-5. 
8. Shin DB, Lee PG, Kim JS, Cho BK. Pseudogout; a case report. J Korean Orthop Assoc 1993; 28: 1906-11.

9. Lim YS, Yoo CD, Lee EB, Park HJ, Song YW. A case of calcium pyrophosphate dihydrate deposition disease that developed at and around the tempormandibular joint. Korean J Med 1996; 51: 563-7.

10. Jeon CH, Choi WH, Ahn JK, Cha HS, Koh JH, Ahn JM, Koh EM. Calcium pyrophosphate dihydrate (CPPD) crystal deposition disease mimicking meningitis: a case report and review of the literature. $J$ Korean Rheum Assoc 2001; 8: 134-9.

11. Song JS, Lee YH, Kim SS, Park W. A case of calcium pyrophosphate dihydrate crystal deposition disease presenting as an acute polyarthritis. J Korean Med Sci 2002; 17: 423-5.

12. Hammoudeh M, Siam AR. Pseudogout in a young patient. Clin Rheumatol 1998; 17: 242-5.

13. Hayashi M, Matsunaga T, Tanikawa H. Idiopathic widespread calcium pyrophosphate dehydrate crystal deposition disease in a young patient. Skeletal Radiol 2002; 31: 246-50.

14. Carpenter MT. Calcium pyrophosphate dihydrate deposition disease. In: West SG, editor, Rheumatology secrets, 2nd ed. Philadelphia: Hanley \& Belfus 2002; 333-8.

15. Halversan PB, Derfus BA. Calcium crystal-induced inflammation. Curr Opin Rheumatol 2001; 13: 221-4.

16. LaPrade RF, Burnett QM. Localized chondrocalcinosis of the lateral tibial condyle presenting as a loose body in a young athlete. Arthroscopy 1992; 8: 258-61.
17. Wright GD, Doherty M. Calcium pyrophosphate crystal deposition is not always 'wear and tear' or aging. Ann Rheum Dis 1997; 56: 586-8.

18. Jones AC, Chuck AJ, Arie EA, Green DJ, Doherty M. Diseases associated with calcium pyrophosphate deposition disease. Semin Arthritis Rheum 1992; 22: 188-202.

19. McGill PE, Grange AT, Royston CS. Chondrocalcinosis in primary hyperparathyroidism. Influence of parathyroid activity and age. Scand J Rheumatol 1984; 13: 56-8.

20. Whyte MP, Murphy WA, Fallon MD. Adult hypophosphatasia with chondrocalcinosis and arthropathy. Variable penetrance of hypophosphatasemia in large Oklahoma kindred. Am J Med 1982; 72: 631-41.

21. McClure J, Smith PS. Calcium pyrophosphate dihydrate deposition in the intervertebral discs in a case of Wilson's disease. J Clin Pathol 1983; 36: 764-8.

22. Canhao H, Fonseca JE, Leandro MJ, Romeu JC, Pimentao JB, Costa JT, Queiroz MV. Cross-sectional study of 50 patients with calcium pyrophosphate dihydrate crystal arthropathy. Clin Rheumatol 2001; 20: 119-22.

23. Dorwart BB, Schumacher HR. Joint effusions, chondrocalcinosis and other rheumatic manifestations in hypothyroidism. a clinicopathologic study. Am J Med 1975; 59: 780-90.

24. Doherty M, Hamilton E, Henderson J, Misra H, Dixey H. Familial chondrocalcinosis due to calcium pyrophosphate dihydrate crystal deposition in English families. Br J Rheumatol 1991; 30: 10-5. 